\title{
A dança na prática pedagógica dos docentes de educação física da rede municipal de ensino de Joinville
}

\section{Dance in the pedagogical practice of physical education teachers in the municipal network of Joinville teaching}

\section{La danza en la práctica pedagógica de profesores de educación física de la red municipal de enseñanza de Joinville}

\author{
iD Silvana de França \\ Universidade de la Empresa, Montevideo, Uruguay \\ e-mail: defranca.silvana@gmail.com \\ iD 9 Pedro Jorge Cortes Morales \\ Universidade da Região de Joinville, Joinville, Santa Catarina, Brasil \\ e-mail: pedromorall@gmail.com
}

\begin{abstract}
Resumo: O objetivo geral deste artigo é analisar a oferta do conteúdo de Dança na prática pedagógica dos professores de Educação Física da rede municipal de ensino de Joinville. A pesquisa é descritiva e explicativa, utilizando o processo misto (quanti-qualitativo). Para tanto, foi aplicado um questionário para 73 professores. Os resultados indicaram que o conteúdo da Dança faz parte do planejamento de alguns deles. Porém, isso ocorre de forma parcial e não convergente em relação ao que propõe a Matriz Curricular. Esse documento orienta que o conteúdo da Dança seja ministrado como cultura corporal do movimento e deve contribuir para o desenvolvimento integral dos alunos.
\end{abstract}

Palavras-chave: Dança. Educação Física. Prática Pedagógica. 
Abstract: The general objective of this article is to analyze the offer of Dance content in the pedagogical practice of Physical Education teachers of Joinville municipal teaching network. The research is descriptive and explanatory, using the mixed process (quanti-qualitative). A questionnaire was applied to 73 teachers. The results indicated that the content of Dance is part of some teachers planning. However, this occurs partially and not convergent in relation to what the Curricular Matrix proposes. This document guides that the content of Dance is taught as the body culture of the movement and should contribute to the students' integral development.

Keywords: Dance. Physical Education. Pedagogical Practice

Resumen: El objetivo general de este artículo es analizar la oferta del contenido de Danza en la práctica pedagógica de los profesores de Educación Física de la red municipal de enseñanza de Joinville. La búsqueda es descriptiva y explicativa, utilizando el proceso mixto (cuanticualitativo). Se aplicó una encuesta para 73 profesores. Los resultados indicaron que el contenido de la Danza es parte de la planificación de algunos profesores. Sin embargo, esto ocurre de manera parcial y no convergente en relación a lo que propone la Matriz Curricular. Este documento orienta que el contenido de la Danza se impartido como cultura corporal del movimiento y debe contribuir al desarrollo integral de los alumnos.

Palabras clave: Danza. Educación Física. Práctica pedagógica.

Submetido em: 29-06-2019

Aceito em: 20-10-2020 
A dança na prática pedagógica dos docentes de educação física da rede municipal... Silvana de França • Pedro Jorge Cortes Morales

\section{Introdução}

Este estudo tem como tema a Dança na prática pedagógica da rede municipal de ensino de Joinville e, mais especificamente, sobre como os professores ministram esse conteúdo para seus alunos nas aulas de Educação Física.

Conforme a Base Nacional Comum Curricular (BNCC) e a matriz curricular de Educação Física deste município (Joinville), a Dança é um conteúdo obrigatório da referida disciplina e deve ser ministrado considerando sua história e sua inserção como elemento da sociedade e da cultura. Sendo assim, evidencia-se a necessidade de que esse conteúdo seja incluído nas práticas docentes de maneira articulada com os documentos normativos acima referidos, oferecendo possibilidades expressivas aos alunos. $\mathrm{Na}$ BNCC (2017), são propostas seis unidades temáticas para serem abordadas nas aulas de Educação Física, no Ensino Fundamental: brincadeiras e jogos, esportes, ginástica, danças, lutas e práticas corporais de aventura.

A importância da pesquisa também está no fato de que não há nenhum estudo sobre esse tema registrado na rede municipal de ensino de Joinville, que é considerada a "Capital Nacional da Dança", sendo que, nela, ocorre anualmente o Festival de Dança de Joinville, reconhecido, internacionalmente, como o maior do mundo em número de participantes. Durante o período do Festival de Dança, inúmeros eventos culturais nas mais diversas áreas acontecem em Joinville, em centros culturais como: centro de eventos, mercado público, teatros, casa da cultura, escolas, universidades, igrejas e praças públicas. Para complementar, no mês de setembro, é realizado o Festival Nacional de Dança Sacra, que foi instituído no município de Joinville e sancionado pela Lei ${ }^{\circ} 8.212$, em abril de 2016. No mês de novembro, acontece o Festival de Dança Escolar, com a participação das escolas, por meio do Programa de Dança na Escola, além de projetos específicos para a modalidade com estudantes da Educação Infantil, Fundamental e Médio, das 
A dança na prática pedagógica dos docentes de educação física da rede municipal... Silvana de França • Pedro Jorge Cortes Morales

redes pública e particular. Há também outros eventos de Dança, como: Mostra de Dança Infantil de Joinville, mostra do Programa Dança das escolas municipais, Mostra Dança Joinville, dentre outros.

Dessa forma, a referida cidade é um marco cultural na Dança e, portanto, é importante o conhecimento desse conteúdo na disciplina de Educação Física, estabelecendo a comunicação nas relações com o contexto social. Para tanto, o docente pode contextualizar a Dança para que ela possa transitar, interferir e possibilitar novas dinâmicas sociais e ser, assim, um agente transformador. Para Marques (2010, p. 138), a Dança "[...] oferta lentes diferentes e diferenciadas que nos possibilitam conhecer, desconstruir, refletir e agir sobre os cotidianos multifacetados do mundo".

Como é ministrado o conteúdo de Dança na prática pedagógica dos professores de Educação Física do Ensino Fundamental II na rede municipal de ensino de Joinville? Com esse questionamento de investigação, compomos a estrutura desta pesquisa. Considerando os aspectos descritos, o apresente artigo tem como objetivo geral analisar a oferta do conteúdo de Dança na prática pedagógica dos professores da rede municipal de ensino de Joinville. Para tanto, foi necessário traçar um perfil dos professores participantes da pesquisa, verificar se o conteúdo da Dança é incluído no planejamento dos professores e quais as metodologias utilizadas e identificar as dificuldades encontradas para a realização desse conteúdo na disciplina de Educação Física da rede municipal de ensino de Joinville.

Sendo assim, a abordagem inicia apresentando a Dança na escola e, posteriormente, nas aulas de Educação Física. Reconhecer a Dança na escola vai além da compreensão corporal e do raciocínio do ato de somente dançar. 
A dança na prática pedagógica dos docentes de educação física da rede municipal... Silvana de França . Pedro Jorge Cortes Morales

A escola pode, sim, fornecer parâmetros para sistematização e apropriação crítica, consciente e transformadora dos conteúdos específicos da dança e, portanto, da sociedade. A escola teria, assim, o papel não de 'soltar' ou de reproduzir, mas sim instrumentalizar e de construir conhecimento em / por meio da dança com seus alunos, pois ela é forma de conhecimento, elemento essencial para a educação do ser social (MARQUES, 2007, p. 23).

O aprendiz de Dança na escola pratica sente, observa, vivencia, reflete, analisa e decodifica sem o uso da palavra; é uma forma de conhecimento de fazer pensar e reconhecer a Dança como manifestação corporal. O corpo está inteiramente no processo de conhecimento da aprendizagem motora, de criação, de percepção corporal e de ressignificação. O ensino e a aprendizagem da Dança, como processo educativo, proporcionam ao educando uma oportunidade em todos os âmbitos, além de possibilitar manifestações de alegria, sendo um canal de expressão das emoções. Aprimora coordenação motora, capacidade intelectual, afetiva, e ainda propicia a exploração de novas formas de movimento corporal e comunicação não-verbal. Condiciona a integração com o meio social para a aprendizagem de novas leituras no mundo, como: vivenciar, refletir, incorporar, tornar-se consciente de seus atos e desenvolver a autonomia (RANGEL, 2002; NANNI, 2003; MARQUES, 2012).

Entende-se, portanto, a importância da Dança no contexto escolar. A escola representa um espaço onde o discente desenvolve atividades socioeducativas e culturais que devem contribuir para seu desenvolvimento e sua aprendizagem de forma significativa. O movimento é inerente ao ser humano, por isso a escola não deve desconsiderar a necessidade do educando de exercer sua cultura corporal. É preciso que sejam oportunizadas situações nas quais os sujeitos possam se expressar em atividades que usem o movimento como linguagem própria, que serve para integrar-se ao meio social. 
A dança na prática pedagógica dos docentes de educação física da rede municipal... Silvana de França • Pedro Jorge Cortes Morales

De acordo com Verderi (2009, p. 69), “[...] a dança, sendo um processo educacional, não se resume simplesmente em aquisição de habilidades, mas poderá contribuir para o aprimoramento das habilidades básicas, dos padrões fundamentais do movimento, no desenvolvimento das potencialidades humanas e em sua relação com o mundo".

Por meio das atividades de Dança educacional, o aprendiz aprimora as habilidades motoras, possibilitando o domínio de seu corpo e conscientização do esquema corporal. Exercer as habilidades e capacidades físico-motoras, como velocidade, força, equilíbrio, agilidade, ritmo, coordenação, flexibilidade, contribuirá para o desenvolvimento motor, para o aprimoramento das possibilidades de movimento, formas, expansão, fluidez, localização espacial e temporal. A Dança possibilita condições para que o educando se movimente, experimente novas formas de expressão corporal e desenvoltura, contribuindo para a sua criatividade e espontaneidade.

A Educação Física é uma prática pedagógica que surgiu de uma necessidade social, religiosa e política, proporcionando várias manifestações em diversas fases que influenciaram em sua caracterização, continuando ainda em constante transformação (CASTELLANI FILHO et al., 2009). O conhecimento da Educação Física, na concepção de González; Schwengber (2012, p. 24), "se materializa e se organiza com base em experiências de movimento. As práticas corporais são meios para explorar o corpo e as possibilidades de ação do sujeito e, ainda, objetos culturais a serem estudados, conhecidos e aprendidos".

Nessa mesma linha de pensamento, González; Fraga (2012, p. 46) afirmam que "a Educação Física é um componente curricular responsável pela tematização da cultura corporal de movimento, que tem por finalidade potencializar o aluno para intervir de forma autônoma, crítica e criativa nessa dimensão social". Por isso, na disciplina de Educação Física, é importante considerar as especificidades da comunidade local para ministrar o conteúdo da Dança. A cidade de Joinville tem como um dos seus marcos culturais a 
A dança na prática pedagógica dos docentes de educação física da rede municipal... Silvana de França • Pedro Jorge Cortes Morales

Dança e, portanto, o conhecimento desse conteúdo na disciplina de Educação Física pode contribuir para estabelecer a comunicação nas relações com o contexto social.

\section{Materiais e métodos}

Quanto ao enfoque, a pesquisa se caracterizou como de cunho quanti-qualitativo, utilizando processos mistos, sendo ainda descritiva e explicativa. O enfoque misto consiste, de acordo com Sampieri, Collado e Lucio (2013, p. 550),

[...] na integração sistemática dos métodos quantitativo e qualitativo em um só estudo, cuja finalidade é obter uma 'fotografia' mais completa do fenômeno. Eles podem ser unidos de tal forma que a abordagem quantitativa e a qualitativa conservem suas estruturas e procedimentos originais ('forma pura dos métodos mistos').

A pesquisa quantitativa tem como objetivo principal, de acordo com Aranda (2015, p. 115), "estudar propriedades e fenômenos quantitativos e suas relações, para explicar e descrever casualmente, generalizar, extrapolar e universalizar. Para isto, modelos matemáticos, teorias e hipóteses que correspondem aos fenômenos naturais". A pesquisa qualitativa, segundo Sampieri, Collado e Lucio (2013, p. 35), se caracteriza como "descrições detalhadas de situações, eventos, pessoas, interações, condutas observadas e suas manifestações".

Os dados quantitativos foram analisados na pesquisa a partir de uma tabulação das respostas aos questionamentos sobre como os docentes ministram o conteúdo da Dança em sua prática pedagógica, bem como os motivos que os levam a trabalhar ou não com esse tema em suas aulas de Educação Física. A análise teve como base dados estatísticos, inseridos no Statistical Package 
A dança na prática pedagógica dos docentes de educação física da rede municipal...

Silvana de França • Pedro Jorge Cortes Morales

for Social Science for Windows (SPSS). Foram levantados a média e o desvio padrão como medidas de tendência central.

Outra característica da pesquisa desenvolvida foi o seu enfoque descritivo, sendo que os dados foram coletados e descritos de forma padronizada. Segundo Gil (2009), as pesquisas descritivas têm como propósito fundamental a descrição das características de determinada população ou fenômeno, ou o estabelecimento de relações entre variáveis. Uma de suas características mais importantes está na utilização de técnicas padronizadas de coleta de dados. Nessa perspectiva, Ferrari (2011, p. 81) argumenta que "trata-se do estudo e descrição das características, propriedade ou relações existentes na comunidade, grupo ou realidade pesquisada, procurando determinar status, opiniões ou projetos futuros nas respostas obtidas".

Também foram identificadas as possíveis razões para a ausência do conteúdo da Dança em algumas aulas de Educação Física. Assim, o estudo teve também características da pesquisa explicativa. Conforme Gil (2009), a característica principal desse topo de pesquisa é a identificação dos fatores que determinam ou que contribuem para a ocorrência dos fenômenos. Essa metodologia aproxima-se do conhecimento da realidade, pois explica a razão, 0 porquê das coisas.

O método de pesquisa utilizado foi o dedutivo. Segundo Gil (2009, p.9), este "é o método que parte do geral e, a seguir desce ao particular. Parte de princípios reconhecidos como verdadeiros e indiscutíveis e possibilita chegar a conclusões de maneira puramente formal, isto é, em virtude unicamente de sua lógica".

\section{Instrumentos de coleta de dados}

Como instrumento de pesquisa, foi utilizado para coleta de dados um questionário composto por um conjunto de 07 questões, sendo seis fechadas e estruturadas para respostas, e uma questão 
A dança na prática pedagógica dos docentes de educação física da rede municipal...

Silvana de França • Pedro Jorge Cortes Morales

aberta para respostas espontâneas. Foram entregues 106 questionários às escolas. Depois, foram devolvidos 73 à pesquisadora, sendo estes validados para a análise dos dados, pois atendiam aos critérios estabelecidos, ou seja, docente atuante na rede municipal de ensino de Joinville na disciplina de Educação Física do Ensino Fundamental II.

No que se refere à população da pesquisa, esta foi composta por 106 professores de Educação Física da rede municipal de ensino de Joinville do Ensino Fundamental II de $6^{\circ}$ ao $9^{\circ}$ ano, sendo 91 efetivos e 15 admitidos em caráter temporário (ACT), que atuam em 53 escolas, no período da pesquisa, sendo este de abril a junho de 2017. A amostra foi probabilística, porque, inicialmente, todos os professores tiveram as mesmas possibilidades de participação. Essa amostra foi composta por 73 professores de 43 escolas que responderam ao questionário enviado pela pesquisadora.

\section{Procedimentos para a análise dos resultados}

Os dados qualitativos foram organizados conforme preconiza a análise de conteúdo de Bardin (2002, p. 38), que “[...] pode ser considerada como um conjunto de técnicas de análises de comunicações, que utiliza procedimentos sistemáticos e objetivos de descrição do conteúdo das mensagens". Sendo assim, foram obedecidas as três fases de análise:

a) pré-análise: Período de organização do material, de intuições, visando a operacionalizar e sistematizar as ideias iniciais para formular um esquema preciso de um plano de análise.

b) exploração do material: A administração sistemática das decisões tomadas, por meio de procedimentos e operação de codificação dos dados, desconto ou enumeração, a partir de regras previamente formuladas.

c) tratamento dos resultados, a inferência e a interpretação: Análise dos resultados brutos para que sejam significativos e vá- 
A dança na prática pedagógica dos docentes de educação física da rede municipal... Silvana de França • Pedro Jorge Cortes Morales

lidos, por meio de operações estatísticas, que possibilitem estabelecer resultados que sintetizam as informações mais relevantes obtidas na pesquisa.

Para análise do perfil dos professores, foram consideradas as fases de desenvolvimento descritas por Huberman (1995), que estudou os ciclos do trabalho dos professores e encontrou sequências que foram classificadas em etapas básicas, conforme os anos de carreira: início da carreira (01 a 03 anos), caracteriza-se como a fase de sobrevivência, descoberta e exploração; a segunda fase é a de estabilização (04 a 06 anos), na qual surge um sentimento de competência e pertença a um corpo profissional; a terceira fase se refere à diversificação ou questionamentos (07 a 25 anos): estágio de experimentação, motivação, busca de novos desafios e/ou momento de questionamentos e reflexão sobre a carreira; a quarta fase corresponde à serenidade e distanciamento afetivo e/ou conservadorismo e lamentações (25 a 35 anos), podendo levar ao conformismo ou ao ativismo; a última fase é de preparação para a aposentadoria, desinvestimento, recuo e interiorização (35 a 40 anos), sendo serena ou amarga.

Para a interpretação dos resultados, foi também utilizado o método de triangulação das informações, por meio do qual foram disponibilizados os dados, os materiais de apoio e a interpretação das informações obtidas. Foram aplicadas estratégias básicas e analíticas, principalmente na análise qualitativa, além da análise intrínseca e a aproximação transversal do conteúdo.

Na definição de Denzin e Lincoln (2006, p. 19), “uso de múltiplos métodos, ou da triangulação, reflete uma tentativa de assegurar uma compreensão em profundidade do fenômeno em questão". Os autores indicam que a triangulação é um meio confiável para a validação da pesquisa. É a alternativa para se empreender múltiplas práticas metodológicas, perspectivas e observadores em uma mesma pesquisa, o que garante rigor, riqueza e complexidade ao trabalho. 
A dança na prática pedagógica dos docentes de educação física da rede municipal...

Silvana de França . Pedro Jorge Cortes Morales

\section{Análises e discussão dos resultados}

\section{a - Perfil dos Professores}

Inicialmente, o questionário teve o intuito de traçar um perfil dos professores participantes, por meio da análise de seus dados sociológicos. Os resultados indicaram que, dos 73 professores respondentes, 100\% têm Licenciatura Plena em Educação Física e se formaram entre os anos de 1982 e 2013. Desses docentes, 83,56\% possuem especialização na área de Educação Física e 16,44\% não fizeram esse curso. Quanto ao mestrado e doutorado, não foi constado nenhum professor com essas formações.

Dentre esses docentes, 54,79\% são do sexo masculino e $45,21 \%$ são do sexo feminino, com a idade entre 23 e 58 anos. 0 percentual de professores efetivos (concursados) é de 91,78\% e $8,22 \%$ são admitidos em caráter temporário. Destaca-se que os 73 professores que participaram da pesquisa trabalham na rede municipal de ensino de Joinville há um período entre 4 meses e 34 anos: 15\% dos docentes de 01 mês a 03 anos de trabalho; 27,40\%, de 04 a 06 anos; 47\%, de 07 a 25 anos; e 4\% atuam na referida rede de 25 a 35 anos. Esses dados apontam que a maioria dos professores (47\%) está na fase de "experimentação e diversificação", de 07 a 25 anos, como classifica Huberman (1995), que organizou os estudos sobre a fase de carreira dos docentes.

Conforme a pesquisa realizada, a maior parte dos docentes encontra-se na terceira fase. É a época da "experimentação e diversificação", entre os 07 e os 25 anos de carreira, que pode ser marcada por novas experiências, mudança de atitude na prática pedagógica visando outras perspectivas. O docente se lança a uma série de novas metodologias, diversificando suas estratégias de ensino por meio de recursos pedagógicos, novas formas de avaliação e condutas em sua prática. 
A dança na prática pedagógica dos docentes de educação física da rede municipal...

\section{b - A Dança na prática pedagógica dos docentes}

A pesquisa mostrou que $30,14 \%$ descreveram que a Dança faz parte de seu planejamento anual; por outro lado, 5,48\% afirmaram que não. Os resultados mostraram ainda que a maioria dos professores, 64,38\%, ministra o conteúdo da Dança em datas comemorativas ou temáticas (festa junina, dia do folclore, Páscoa e dia da criança etc.). Nesse sentido, são realizadas apresentações de coreografias com os alunos que se dispuserem a participar (Gráfico 01).

\section{Gráfico 1 - A Dança no planejamento anual dos docentes.}

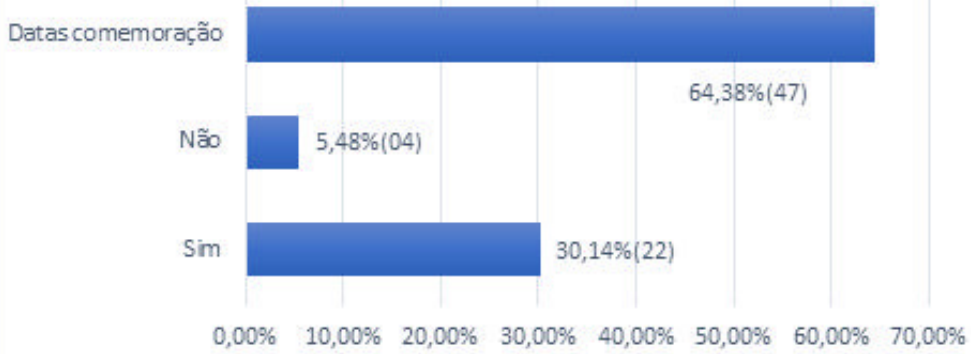

Fonte: França (2017).

Essas evidências apontam que a maior parte dos professores insere a Dança como conteúdo em seu planejamento anual, porém, dentre eles, também existe uma maioria que atende às necessidades da escola em datas comemorativas, nas quais a Educação Física é solicitada a fazer coreografias para apresentações em eventos.

Conforme a Matriz Curricular de Educação Física do Município de Joinville (JOINVILLE, 2011), nos anos finais do Ensino Fundamental II, o conteúdo da Dança está presente em todos os trimestres do ano letivo. Esse conteúdo está selecionado de forma específica para o docente inserir em seu planejamento, que engloba pesquisar a teoria sobre o contexto histórico e social das diversas manifestações de Dança, abrangendo a diversidade de danças folcló- 
A dança na prática pedagógica dos docentes de educação física da rede municipal...

Silvana de França • Pedro Jorge Cortes Morales

ricas, de salão, regionais, dentre outras, considerando a cultura local. Para tanto, é importante o estudo dos conceitos, discussões de ideias e atividades práticas, visando o desenvolvimento motor, cognitivo e afetivo.

\title{
Gráfico 02 - Motivos para não ministrar o conteúdo de Dança na disciplina de Educação Física.
}

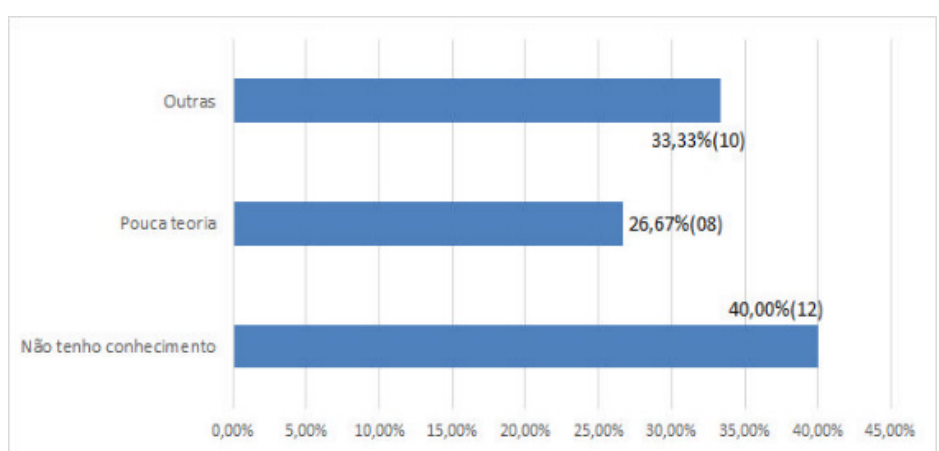

Fonte: França (2017).

As justificativas apresentadas pelos professores que responderam negativamente à questão anterior foram: 40\% afirmaram que não têm o conhecimento da prática da Dança; $26,67 \%$ enfatizaram que, no curso de graduação de Educação Física, tiveram pouca teoria e prática; e 33,33\% apontaram outros motivos, tais como: pouca habilidade para a prática, desinteresse dos alunos, pouco espaço e equipamentos para ministrar a aula e falta de apoio da escola (Gráfico 02). Conforme as pesquisas desenvolvidas por Cortes Morales (2012, p. 48),

\begin{abstract}
é possível entender que a formação de professores ocorre através da interação entre o conhecimento adquirido na universidade, as experiências obtidas no trabalho diário, a conscientização, a discussão e a participação das diferentes situações de ensinoaprendizagem.
\end{abstract}

Para Cone (2015), Dança é um conteúdo essencial na grade curricular de Educação Física que prima pela qualidade. É impor- 
A dança na prática pedagógica dos docentes de educação física da rede municipal...

Silvana de França • Pedro Jorge Cortes Morales

tante oportunizar que os discentes desenvolvam suas habilidades de movimento com o objetivo funcional ou de expressão. Assim, é possível realizar experiências que permitem descobrir as possibilidades inerentes ao movimento.

Na sequência da pesquisa, os professores foram questionados sobre o processo de ensino do conteúdo de Dança em suas aulas. As respostas apontaram que: $46,58 \%$ voltaram a enfatizar as apresentações em datas comemorativas; $16,44 \%$ afirmaram que 0 ensino se dá por meio do estudo do contexto histórico e social da Dança; $13,70 \%$ enfatizaram os meios de comunicação (filme, jornal, revista, audiovisual e internet) como importantes mecanismos para efetivação deste processo de ensino; 8,22\% indicaram que não têm o conhecimento deste conteúdo de Dança. Os demais professores (12,33\%) citaram as atividades rítmicas expressivas, brincadeiras de roda e pequenas coreografias utilizando: rap, funk, street dance, jazz, dança de salão dentro de um contexto didático. Nessa questão, 1,37\% não responderam e 1,37\% assinalaram a alternativa "outros", mas não especificaram nenhum procedimento (Gráfico 03).

\section{Gráfico 03 - Ensino do conteúdo da Dança.}

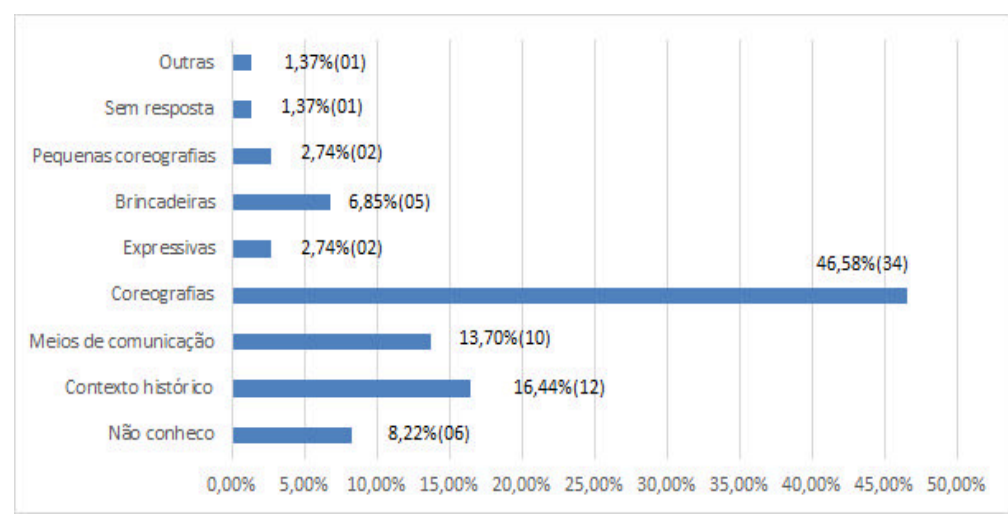

Fonte: França (2017).

A Matriz Curricular de Educação Física do Município de Joinville (JOINVILLE, 2011), nos anos finais do Ensino Fundamental II, indica procedimentos que podem ser usados no desenvolvimento de ati- 
A dança na prática pedagógica dos docentes de educação física da rede municipal... Silvana de França • Pedro Jorge Cortes Morales

vidades rítmicas expressivas, desde sua contextualização histórica e social, além de suas práticas corporais.

Como enfatiza Marques (2010), nas aulas de Dança, é possível ensinar passos, sequências, memorização, como, por exemplo, ao dançar a "Quadrilha" (repertório de danças brasileiras), o aluno deverá compreender seu significado, importância de seu contexto cultural, o que Dança, onde Dança. As aulas focadas somente no aprendizado de passos limitam o ensino da compreensão do movimento, trajetórias, espaços, fluxo, criatividade, expressividade.

Quanto à forma pela qual os professores oportunizam que os alunos desenvolvam o conhecimento corporal do movimento nas aulas de Dança, $49,32 \%$ o fazem por meio de atividades práticas, como a elaboração de coreografias; $13,70 \%$ usam os meios de comunicação; 13,70\% optam pelas atividades teóricas; 10,96\% afirmaram que não têm o conhecimento desse conteúdo de Dança; e $8,22 \%$ assinalaram o item "outros", indicando que não inserem a Dança no planejamento ou não trabalham esse conteúdo porque há muita resistência dos alunos; 4,11\% não responderam a essa questão. Evidencia-se que a grande maioria dos professores somente desenvolve o ensino do conteúdo de Dança nas aulas de Educação Física, especialmente nas aulas práticas, por meio da elaboração de coreografias.

Na visão de Garcia (2011, p. 100),

\begin{abstract}
Trabalhar o corpo através da dança é apresentar ao aluno uma nova proposta de educá-lo, que lhe dará a liberdade de expressarse e, a partir daí, desenvolver sua criatividade, explorando as diversas possibilidades de movimento que o seu corpo permite. Torna-se necessário ampliar seu leque de movimentos enquanto ser completo, sem impor-lhe técnicas rígidas.
\end{abstract}

Na concepção de Vargas (2009), a Dança está inserida como um dos conteúdos da cultura corporal de movimento. Ela representa um grande potencial educativo, uma vez que possui característica 
A dança na prática pedagógica dos docentes de educação física da rede municipal...

Silvana de França • Pedro Jorge Cortes Morales

integradora dos domínios humanos, além de possibilitar o descobrimento da corporeidade, da sensibilidade e da expressividade.

Foi constatado ainda que os professores encontram dificuldades para a aplicação do conteúdo de Dança na unidade escolar. Os principais problemas levantados foram: $24,66 \%$ indicaram a falta de espaço físico; 23,29\% afirmaram que as turmas são mistas (formadas por alunos do gênero feminino e do masculino) e têm um grande número de alunos; $13,70 \%$ apontaram a falta de material didático; $13,70 \%$ que o preconceito existe no ambiente escolar, pois muitos acreditam que a Dança deveria ser trabalhada somente com o gênero feminino; 10,96\% não têm o conhecimento deste conteúdo; e 10,96\% não trabalham a Dança devido à resistência dos alunos; houve uma abstinência de $2,74 \%$ dos respondentes (Gráfico 04).

\section{Gráfico 04 - Dificuldades para a realização do conteúdo da Dança.}

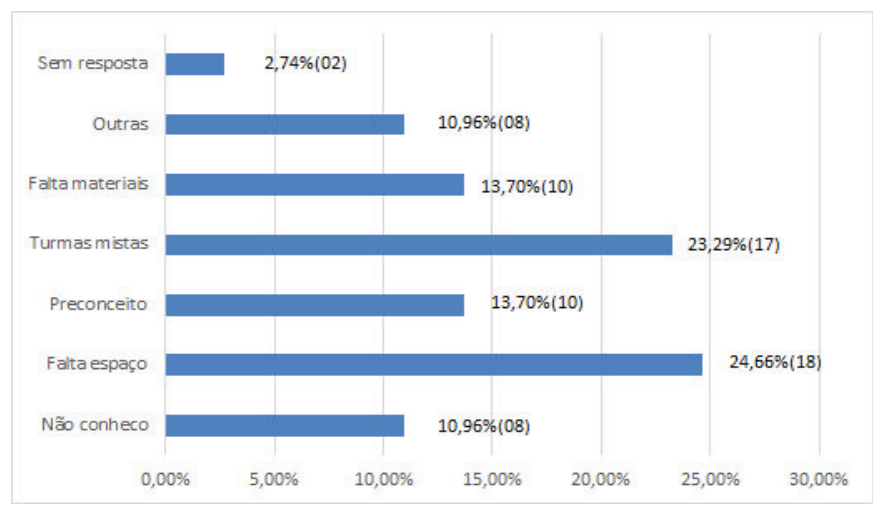

Fonte: França (2017).

As alegações dos professores quanto à infraestrutura das escolas para desenvolver as aulas de Dança estão ligadas aos espaços restritos que são destinados para esse fim, uma vez que os auditórios e o pátio da escola são utilizados por todas as disciplinas, o que limita o trabalho do professor. Também o material didático, como aparelho de multimídia, é compartilhado pelos docentes nas várias áreas de ensino. $\mathrm{O}$ grande número de alunos por sala (em 
A dança na prática pedagógica dos docentes de educação física da rede municipal... Silvana de França • Pedro Jorge Cortes Morales

média 35), com turmas mistas, no entendimento dos docentes que participaram da pesquisa, caracteriza-se como um problema.

Uma análise dos Projetos Políticos Pedagógicos das escolas nas quais foi realizada a pesquisa, demonstrou que a grande maioria delas $(91 \%)$ possui quadras poliesportivas. Todas as escolas que fizeram parte da pesquisa também têm multimídia, que deve ser compartilhada por todas as disciplinas, havendo um agendamento para o uso desse recurso pedagógico. Sendo assim, uma possibilidade para que os professores conseguissem ministrar suas aulas de forma planejada seria utilizando as quadras poliesportivas, tendo um espaço mais amplo para atender todos os alunos, independente se forem turmas mistas ou não. $O$ uso dos recursos multimídia também pode contribuir para diversificar as metodologias nas práticas pedagógica dos professores. Todos esses elementos poderiam incentivar o interesse dos alunos.

Foram questionados os motivos pelos quais os professores não ministram o conteúdo de Dança em suas aulas. Dentre os 73 entrevistados, somente 46 docentes responderam à última questão da pesquisa. Os resultados obtidos indicam que $11 \%$ não têm o conhecimento desse conteúdo; $20 \%$ têm pouco conhecimento; 18\% afirmaram que não têm habilidade para esse conteúdo; e 11\% não têm domínio nesse aspecto específico da Dança. Portanto, na categoria pessoal, os motivos apontados perfazem um total de $60 \%$, indicando que a maioria dos docentes que respondeu a essa questão apresenta algum motivo pessoal para não ministrar o conteúdo da Dança em suas aulas.

Quanto ao ambiente, $4 \%$ evidenciaram que o espaço físico da escola é inadequado e $2 \%$ indicaram a falta de material didático como uma das causas para não ministrar o conteúdo da Dança.

No que se refere ao processo pedagógico, $18 \%$ responderam que há falta de interesse dos alunos; $9 \%$ enfatizaram que trabalham a Dança somente na composição coreográfica da festa Junina; $4 \%$ relataram que é difícil trabalhar com turmas mistas; $2 \%$ indicaram que a Matriz Curricular do município de Joinville não contempla o 
A dança na prática pedagógica dos docentes de educação física da rede municipal...

Silvana de França • Pedro Jorge Cortes Morales

conteúdo de Dança; e 2\% apontaram que, na Matriz Curricular, há muitos conteúdos a serem trabalhados e, por isso, não há tempo para o conteúdo da Dança. De acordo com Medeiros e Santos (2014, p. 91),

[...] as aulas de Educação Física ao desenvolver a dança devem ser ministradas como qualquer outra aula, sendo necessário para isso considerar os objetivos estabelecidos e a disposição do professor para que a aula aconteça, atribuindo a devida importância a este conteúdo desde o planejamento da aula até a sua execução e avaliação.

Nota-se que os docentes demonstram que, em algumas situações, não se sentem preparados e também acreditam não terem habilidade para ministrarem o conteúdo da Dança na disciplina de Educação Física, havendo casos em que eles alegam que tais problemas ainda estão aliados à falta de interesse de alunos, falta de espaço e material adequado.

\section{Considerações finais}

Nesta pesquisa foi constatado que apenas a minoria dos professores de Educação Física da rede municipal de ensino de Joinville insere o conteúdo da Dança em sua prática pedagógica e, quando o fazem, não está de forma convergente com a proposta da Matriz Curricular. Foram verificadas as dificuldades que os docentes de Educação Física encontram para a realização da atividade da Dança em sua prática pedagógica, tais como: espaço inadequado, a dificuldade de trabalhar com turmas mistas (compostas por estudantes do gênero masculino e feminino), falta de material didático, preconceito em relação ao gênero masculino participar das atividades de Dança.

Esses desafios que se apresentam no cotidiano escolar, e que os professores participantes da pesquisa consideram como 
A dança na prática pedagógica dos docentes de educação física da rede municipal... Silvana de França • Pedro Jorge Cortes Morales

dificuldades, precisam ser enfrentados para que o conteúdo da Dança seja devidamente ministrado. Os docentes devem elaborar um planejamento adequado considerando a disponibilidade de espaço físico e os recursos de multimídia existentes na escola.

Quanto ao número de alunos na sala (em média 35), com turmas mistas, o professor pode aproveitar essa diversidade para desenvolver dinâmicas que proporcionem a socialização e interação entre meninos e meninas. Há diversos gêneros de Dança que podem ser melhor desenvolvidos por meio de coreografias que tenham a participação dos dois gêneros. Foi também possível investigar as metodologias e as estratégias empregadas pelos professores no ensino da Dança, uma vez que eles utilizam pouco os recursos tecnológicos, como a multimídia, lousa digital, tablet, para contextualizar, conhecer e pesquisar as manifestações da cultura corporal de movimento, podendo situar a Dança em seu contexto histórico social.

Quando a escola centraliza suas abordagens nos jogos pré-desportivos, o discente deixa de ter um conhecimento plural que Ihe é assegurado pelo currículo escolar. É importante que os professores se preparem para enfrentar o desafio de trabalhar com a multiplicidade de situações que são propostas no processo curricular. Os alunos têm o direito de ter o conhecimento sobre o conteúdo da Dança, seus gêneros e ritmos, aprendendo as possibilidades de utilizá-la como forma de expressão e comunicação com o meio social.

Fica comprovada, assim, a relevância de que os docentes insiram, em seu planejamento, metodologias e estratégias que contribuam para a diversificação das aulas, abordando o conteúdo da Dança de forma dinâmica, considerando o contexto social da cidade de Joinville. Sendo esta a capital nacional Dança, podem ser valorizadas as manifestações existentes no meio social para estimular os adolescentes ao estudo deste tema. 
A dança na prática pedagógica dos docentes de educação física da rede municipal... Silvana de França • Pedro Jorge Cortes Morales

\section{Referências}

ARANDA, Tomás Jesús Campoy. Metodología de la investigación científica. Ciudad del Este: Escuela de Posgrado, Universidad Nacional del Este, 2015. 497 p.

BARDIN, L. Análise de conteúdo. Trad. de Luís Antero Reto e Augusto Pinheiro. Lisboa: Edições 70, 2002.

BRASIL. Ministério da Educação. Base Nacional Comum

Curricular. Brasília: MEC, 2017. Disponível em http://basenacionalcomum.mec.gov.br/images/BNCC publicacao.pdf. Acesso em: 10 out. 2017.

CASTELLANI FILHO, L. et al. Metodologia do ensino de Educação Física. 2 ed. São Paulo: Cortez, 2009.

CORTES MORALES, Pedro Jorge. La capacitación profesional continua para el aprovechamiento de los nuevos saberes en educación física. 2012. Tese (Doctorado en Ciencias de la Educación) - Universidad de Jaén, España, 2012.

CONE, Thereza Purcell. Ensinando dança para crianças. Trad. de Lúcia Helena de Seixas Brito e Soraya Imon de Oliveira. 3 ed. Barueri, SP: Manole, 2015.

DENZIN, N. K.; LINCOLN, Y. S. Introdução: a disciplina e a prática da pesquisa qualitativa. In: DENZIN, N. K.; LINCOLN, Y. S. e colaboradores. $\mathrm{O}$ planejamento da pesquisa qualitativa: teorias e abordagens. 2. ed. Porto Alegre: Bookman e Artmed, 2006. p. 15-41.

FERRARI, Elisa; et al. Pesquisa Descritiva. In: SANTOS, Saray Giovanas dos. Métodos e Técnicas de Pesquisa Quantitativa Aplicada à Educação Física. Florianópolis: Tribo da Ilha, 2011. GARCIA, Ângela. Dança: caminhos, reflexões e descobertas. Canoas: ULBRA, 2011.

GIL, Antonio Carlos. Métodos e técnicas de pesquisa social. 6 . ed. São Paulo: Atlas, 2009. 
A dança na prática pedagógica dos docentes de educação física da rede municipal...

Silvana de França • Pedro Jorge Cortes Morales

GONZÁLEZ, F. J.; FRAGA, A. B. Afazeres da Educação Física na escola: planejar, ensinar, partilhar. Erechim: Edelbra, 2012. GONZÁLEZ, F. J.; SCHWENGBER, M. S. V. Práticas pedagógicas em Educação Física: espaço, tempo e corporeidade. Erechim: Edelbra, 2012.

HUBERMAN, Michael. O Ciclo de vida profissional dos professores. In: NÓVOA, A. (Org.). Vidas de professores. 3. ed. Portugal: Porto Editora, 1995. p. 31-61.

JOINVILLE. Matriz Curricular da Secretaria de Educação do Município de Joinville, educação Física. Joinville: Secretaria da Educação, 2008.

JOINVILLE. Matriz Curricular da Secretaria de Educação do Município de Joinville, educação Física. Joinville: SEC, 2011. Disponível em: https://intranet.joinville.sc.gov.br. Acesso: jul. 2016.

JOINVILLE. Lei Ordinária 8.212, de 27 de abril de 2016. Institui o "Festival Nacional de Dança Sacra" no município de Joinville. Joinville, 27 abr. 2016 MARQUES, Isabel A. Dançando na escola. 4. ed. São Paulo: Cortez, 2007.

MARQUES, Isabel A. Linguagem da dança: arte e ensino. São Paulo: Digitexto, 2010.

MARQUES, Isabel A. Interações: crianças, dança e escola. São Paulo: Blucher, 2012. (Coleção Interações).

MEDEIROS, Ana Gabriela Alves; SANTOS, Soraya Ramini Sena. A Dança como Conteúdo das Aulas de Educação Física: uma Perspectiva a Partir dos Parâmetros Curriculares Nacionais. In: V CONGRESSO NORDESTE DE CIÊNCIAS DO ESPORTE. 5, 2014, Guanambi, BA. Anais. Guanambi, Bahia, 2014. p. 85-92

NANNI. Ensino da dança: enfoques neurológicos, psicológico e pedagógicos na estruturação/expansão da consciência corporal e da auto-estima do educando. Rio de Janeiro: Shape, 2003. 
A dança na prática pedagógica dos docentes de educação física da rede municipal... Silvana de França • Pedro Jorge Cortes Morales

RANGEL, Nilda Barbosa Cavalcante. Dança, educação, educação física: propostas de ensino da dança e o universo da Educação Física. Jundiaí: Fontoura, 2002.

SAMPIERI, Roberto Hernández; COLLADO, Carlos Fernàndez; LUCIO, María del Pilar Baptista. Metodologia de pesquisa. Trad. de Daisy Vaz de Moraes. Revisão técnica de Ana Gracinha Queluz Garcia, Dirceu da Silva, Marcos Júlio. 5. ed. Porto Alegre: Penso, 2013.

VARGAS, L. A. M. de. Escola em dança: movimento, expressão e arte. Porto Alegre: Mediação, 2009.

VERDERI, Érica. Dança na escola: uma abordagem pedagógica. São Paulo: Phorte, 2009.

\section{Aprovação de comitê de ética em pesquisa}

Pesquisa aprovada pelo Comitê de Ética do INSTITUTO SUPERIOR E CENTRO EDUCACIONAL LUTERANO BOM. Título: A Relação entre a proposta da matriz curricular de educação física e o conteúdo da Dança na prática pedagógica dos professores.

\section{Publisher}

Universidade Federal de Goiás. Faculdade de Educação Física e Dança. Publicação no Portal de Periódicos UFG. As ideias expressadas neste artigo são de responsabilidade de seus autores, não representando, necessariamente, a opinião dos editores ou da universidade. 